\title{
O AMBIENTE E AS MEMÓRIAS DOS ÍNDIOS XUKURU SOBRE O IPOJUCA E A BARRAGEM PÃO-DE-AÇÚCAR
}

\section{THE ENVIRONMENT AND THE MEMORIES OF THE XUKURU INDIANS ON THE IPOJUCA AND THE BARRAGEM BREAD-OF-SUGAR}

Denise Batista de Lira*

\begin{abstract}
Resumo: A bacia do rio Ipojuca abrange uma área de 3.435,34 $\mathrm{Km}^{2}$ correspondendo a 3,49\% da área do Estado de Pernambuco. Está inserido nessa bacia um total de 25 municípios, dentre eles Poção e Pesqueira, situados no Agreste pernambucano, localidades onde se encontra a Área Indígena Xukuru. O Ipojuca é atualmente o terceiro rio mais poluído do Brasil e tem sido objeto de estudos visando programas de revitalização propostos por ONGs e entidades governamentais. Os índios Xukuru estabelecem uma relação com o citado rio, pois retiram dele e da Barragem alimentada pelas águas do Ipojuca, o sustento, ou seja, a pesca, que serve tanto para o consumo doméstico quanto para a venda. As águas da Barragem também são destinadas a agricultura e a pecuária na região. Para compreender essa relação, utilizaremos as memórias, pois ela está "associada à percepção de pertencimento a um mundo que engloba e constitui os indivíduos" (SANTOS, 2009:16).
\end{abstract}

Palavras chave: índios Xukuru, rio Ipojuca, Ambiente, memórias

Abstract: Ipojuca river basin covers an area of $3,435.34$ square kilometers representing $3.49 \%$ of the state of Pernambuco. Is inserted in the basin a total of 25 municipalities, including Poção and Pesqueira, located in Pernambucan, locations where is the indigenous area Xukuru. The Ipojuca is currently the third most polluted river in Brazil and has been the subject of studies aimed at revitalization programs offered by NGOs and government entities. The Xukuru establish a relationship with the river and with dam, which is fed by the waters of Ipojuca, because of the fishing, which caters for both domestic consumption and for sale. The waters of the dam are also used for farming and ranching in the region. To understand this relationship, we will use the memories, because it is "associated with the perception of belonging to a world that encompasses and represents individuals" (SANTOS, 2009:16).

Key words: Indians Xukuru, river Ipojuca, environment, memoirs.

\section{Introdução}

Situada em uma área intermediária entre o litoral e o Sertão, o Agreste pernambucano tem espaços subumidos e semiáridos, revelando assim suas peculiaridades. Os espaços úmidos são os brejos de altitude, onde o índice pluviométrico é acima da média da região, ou seja, entre 800 e $1.200 \mathrm{~mm}$. Devido às chuvas mais constantes e a altitude, o solo e vegetação ganham aspectos diferenciados; solos ricos em materiais orgânicos e vegetação mais densa. A Serra de Ororubá, no município de Pesqueira apresenta semelhantes características, e por esse motivo, tem sido desde o princípio do processo de colonização portuguesa naquela região, alvo de disputas entre diversos grupos sociais. Contudo, anterior a colonização, a Serra era habitada pelo povo indígena Xukuru, que tiveram suas terras espoliadas e sua identidade étnica negada (SILVA, 2008). O processo de "retomada"1 das terras pelos indígenas ocorreu a partir da Década

\footnotetext{
* Possui graduação em Licenciatura plena em História pela Universidade Federal Rural de Pernambuco (2007) e Especialização pela mesma instituição e na mesma área, concluído em 2009. Cursando mestrado em História pela UFPE.

${ }^{1}$ Nome atribuído pelos indígenas ao processo e a ação de reocupar terras tradicionais, ou seja, que pertenciam a seus antepassados e que foram expropriadas por fazendeiros e/ou pequenos posseiros.
} 
de 1990 do século passado e é concretizada em 2001 com a demarcação e homologação do território (OLIVEIRA, 2006). Esse período deu início a uma nova relação com a terra e a utilização de seus recursos, e é esse ponto que pretendemos evidenciar no presente texto, dando ênfase as memórias por entender que "a memória é associada à percepção de pertencimento a um mundo" (SANTOS, 2009:16).

\section{Aspectos geográficos e socioeconômicos de Pesqueira}

O Agreste pernambucano constitui uma zona de transição entre o litoral úmido e 0 Sertão semiárido. Possui uma área de $24.714 \mathrm{~km}^{2}$, o que corresponde aproximadamente a 25\% do Estado de Pernambuco. Essa região apresentada uma estrutura espacial diversificada em suas condições mesológicas refletindo nos aspectos socioeconômicos locais (LINS, 1989).

O geógrafo Mário Lacerda de Melo (1980) caracterizou o Agreste e seu papel desempenhado em âmbito regional como importante em decorrências de alguns fatores tais como; possuir cerca de $25 \%$ da população do Estado; abastecimento de gênero alimentícios destinados principalmente ao litoral; fornecedor de mão-de-obra em determinados períodos do ano a Zona da Mata. Melo ressaltou também em Os agrestes: estudos dos espaços nordestinos do sistema de gado-policultura de uso de recursos, as "áreas de exceção" espaços subúmidos e úmidos como, os brejos de altitude, que devido ao alto índice pluviométrico e altitude possibilitam lavouras diferenciadas e com maior produtividade, pois os solos são mais profundos e ricos em materiais orgânicos e o acesso a recursos d'água é maior.

Os brejos de altitudes do Agreste pernambucano fazem parte do Planalto da Borborema, que é um conjunto de pequenos e grandes maciços e cristais residuais eminentes sobre um grande aplainamento. Dentre alguns municípios que integram esse planalto, está Pesqueira, onde se localizada a Serra de Ororubá, região de destaque, pela elevada altitude, que em determinadas áreas pode ultrapassar os 1.000 metros, pela vegetação, solo, clima e presença quase constante de cursos d'água, que inclusive abastecem todo o município (SILVA, 2007).

Devido a essas potencialidades, Pesqueira tem tanto produção de lavouras para subsistência quanto para a comercialização, seja na própria cidade, seja para os mercados de outros municípios. Na sua produção destacam-se as hortaliças como, tomate, cenoura, pimentão, alface e beterraba e também em frutas como banana e goiaba, além dos grãos como, feijão e milho. Atualmente parte desses produtos agrícolas é produzida pelos índios Xukuru que habitam o município, principalmente na área rural.

A presença indígena na região é relatada nos documentos coloniais, sendo a ocupação efetivada a partir do século XVII (ALMEIDA, 1980). A área demarcada oficialmente representa 
cerca 27.555 mil hectares que os próprios índios a dividem em três regiões socioambientais: 0 Agreste, a Ribeira e a Serra, onde se situam 24 aldeias. A região da Ribeira é cortada pelo rio Ipojuca.

O município de Pesqueira dispõe de recursos hídricos, mas estes estão na área rural, onde os aqüíferos são utilizados principalmente na produção de gêneros alimentícios e criação de pecuária leiteira. Devido a esse fator a cidade e alguns distritos como, Mutuca, Salobro, Papagaio, Ipanema e Mimoso enfrentam problemas no abastecimento de água.

Esses distritos se abastecem por meio de poços, aquisição de água no comércio ou por meio de carros pipas, fornecidos pela Prefeitura, sendo a qualidade da água um critério pouco observado. A questão não se restringe apenas ao seu fornecimento e nem à existência ou a inexistência de fontes provedoras desse produto natural, mas aos poucos investimentos públicos para prover água para os habitantes do município e as formas de armazenamento e transportes utilizadas pela população na ausência desse sistema de esgoto e água encanada.

O governo estadual desenvolveu um projeto, que está em período de concretização, a fim de trazer melhorias no abastecimento dessa região, conhecido como O Sistema Adutor do Agreste, que atenderá 61 municípios, dentre eles; Belo Jardim, Tacaímbo, São Caetano, Caruaru, Bezerros, Gravatá e Pesqueira, destacando-se o atendimento a área urbana. Esse adutor utilizará as águas do Ipojuca, embora outras bacias, como as dos rios Moxotó, Capibaribe, Unam, Paraíba, Serinhaém, Mundaú e Ipanema, participem de forma indireta.

Para demonstrar os possíveis e prováveis impactos na construção do adutor para 0 Ambiente, inclusive para a população que vive na área na qual ele será implantado, elaborou-se o RIMA (Relatório de Impacto Ambiental). Esse relatório traz informações sobre a pedologia, hidrologia, geomorfologia, fauna e a flora da região onde será construído o sistema adutor, demonstrando os prejuízos e benefícios da obra. Com o RIMA também é ressaltada a importância da conservação e pleiteada a disponibilização da ictiofauna, devido a presença de famílias que obtém o seu sustento através da pesca, fato que ocorre dentro e fora do território indígena.

Quanto aos impactos ambientais na região podemos relacionar: aumento de tráfego, ruídos e doenças, principalmente as doenças sexualmente transmissível (DST) e conseqüentemente maiores demanda pelo serviço público de saúde; diminuição do êxodo na região e pressão sobre a infraestrutura urbana dos municípios "atingidos" pelo sistema adutor; risco de comprometimento do patrimônio arqueológico; perda de vegetação nativa e habitats da fauna terrestres, além de modificações na composição das comunidades biológicas aquáticas nativas. Os benefícios gerados pelo adutor são: oferta de água de boa qualidade e de maneira 
mais contínua para as áreas urbanas e rurais; a geração de empregos durante a fase de construção e o próprio desenvolvimento econômico e social da região.

O historiador alemão, Dieter Schott, em seu artigo, Urban environmental history: what lessons are there to be learnt?, discorreu sobre a importância da compreensão das alterações humanas provocadas no espaço físico das cidades, pois o Ambiente não é apenas o meio natural, ou a Natureza intocada ou parcialmente intocada, mas todo o espaço que circunda os seres humanos. Entender o surgimento de algumas "necessidades", como o provimento de água, mesmo longe de sua fonte, e perceber as ações humanas para satisfazer essa exigência, faz parte da História Ambiental Urbana. Schott afirmou: "The city was conceived as a quasi organism; water pipes and sewage systems would act like the body's blood circulation to keep the city functioning and prevent it from being poisoned through its own waste products"(2004). ${ }^{2}$

A História Ambiental é uma corrente historiográfica que discute a relação dos os seres humanos com o Ambiente natural, buscando compreender como "lidar com o papel e o lugar da Natureza na vida humana, e estudar todas as interações que as sociedades do passado tiveram com o mundo não humano, o mundo que não criamos em nenhum sentido primário". (WORSTER, 2003:25). Uma característica particular da História Ambiental é propor e dispor da interdisciplinaridade, ou seja, utilizar diversas ciências como a Biologia, Geografia, Geologia, Arqueologia, Sociologia, etc., no processo da escrita histórica.

Além da interdisciplinaridade a História Ambiental propõe estudos que abranjam a longa e a curta duração. $O$ tempo e a história são processos onde se estabelece uma interligação, sendo o tempo um elemento fundamental aos estudos históricos. Com um movimento de múltiplas características e ritmos, o tempo está inserido na vida humana, demonstrando suas rupturas e continuidades e o historiador além de ser influenciado por essas representações tem na cronologia seu instrumento de trabalho.

Entretanto, os historiadores ambientais alvitram uma revolução nos marcos cronológico de compreensão do mundo ao dispor a natureza como sujeito histórico, tal qual o homem (PÁDUA, 2010). A natureza é apresentada como algo em construção e reconstrução ao longo do tempo e os historiadores ambientais repensam o lugar do ser humano neste quadro mais amplo do planeta, propondo uma interação entre ambiente e sociedade, ou seja, as interações e influências entre os sistemas sociais e os sistemas naturais e as conseqüências dessas influências e interações para ambos os sistemas no decorrer do tempo.

\footnotetext{
2 "A cidade foi concebida como um quase organismo; canos de água e sistema de esgoto agiria como a circulação do sangue no corpo para manter o funcionamento da cidade e impedir que ela seja envenenada através dos seus próprios resíduos".
} 
Devido a essa inter-relação entre sistemas sociais e sistemas naturais, os historiadores ambientais não devem "visitar" as ciências naturais, mas estabelecer uma associação direta, pois além de "aliadas" elas integram o próprio objeto de estudo, são fundamentais para a compreensão do uso dos recursos naturais, visto que as diversas culturas exploram a Natureza de diferentes formas de acordo com suas necessidades, que por si estão atreladas ao tempo e espaço. O pesquisador José Augusto Drummond acrescenta sobre essa nova historiografia "A História Ambiental sintetiza muitas contribuições na prática interdisciplinar e sua originalidade está na sua disposição explícita de "colocar a sociedade na natureza"." (1991:184). Por compreender a importância do Ambiente na história humana, neste texto iremos priorizamos esse viés.

\section{0 rio Ipojuca: aspectos naturais, socioeconômicos e ambientais}

O Ipojuca tem sua nascente em Arcoverde, município vizinho a Pesqueira, a uma altitude de 876 metros e percorre várias cidades do Agreste, Zona da Mata e Litoral. A bacia do já citado rio, abrange uma área de $3.435,34 \mathrm{Km}^{2}$ correspondendo a $3,49 \%$ da área do Estado de Pernambuco.

O percurso do Ipojuca, com cerca de $320 \mathrm{~km}$, tem o seu regime intermitente, sendo perene a partir de seu médio curso, nas proximidades da cidade de Caruaru. Este rio é considerado bastante poluído devido a lançamento de dejetos domésticos e industriais, fazendo parte atualmente de campanhas que são voltadas para sua limpeza e conservação.

O CPRH (Companhia Pernambucana de Recursos Hídricos) em parceria com 0 Ministério do Meio Ambiente desenvolveu um estudo em 2003 sobre as fontes poluidoras da Bacia do Rio Ipojuca. Esse projeto destacou a participação das cidades e regiões na degradação do rio apresentando os seguintes percentuais: $84,2 \%$ referente ao Agreste; $13,3 \%$ para a Zona da Mata; 2,2\% para o Litoral e apenas 0,3\% para o Sertão. $O$ relatório também ressalta que "os efluentes industriais é muito superior aos esgotos domésticos e causam ao rio maior impacto" (CPRH, 2003:21).

$O$ aumento de efluentes domésticos e industriais lançados no rio ocorreu devido ao crescimento populacional e industrial das cidades do Agreste, principalmente Caruaru, que sozinha é responsável por $40 \%$ do despejo dos dejetos. Quanto à Zona da Mata, a segunda região que mais polui o Ipojuca, é atribuída ao setor sucroalcooleiro maior responsabilidade por essa ação.

A dinâmica do crescimento das cidades não resultou em modificações imediatas nas ações do poder público quanto a políticas voltadas para o tratamento desses resíduos. Embora 0 
Capítulo VI do Artigo 225 da Constituição Federal de 1988 afirme: "Todos têm direito ao meio ambiente ecologicamente equilibrado, bem de uso comum do povo e essencial à sadia qualidade de vida, impondo-se ao Poder Público e à coletividade o dever de defendê-lo e preservá-lo" (CONSTITUIÇÃO FEDERAL, 1994:183).

A bacia do rio Ipojuca tem sido objeto de estudos de Comitês, do Programa Nacional do Meio Ambiente, em workshops, dissertações etc., a fim de propor medidas para revitalização desse ecossistema. Para compreendermos melhor esses projetos é necessário definir o que é bacia hidrográfica:

É um conjunto de terras drenadas por um rio principal e seus afluentes. Mas ao tratar uma bacia como unidade de gestão, tal como propõe a Política Nacional de Recursos Hídricos, a base para se definir um escopo de ação resulta na própria bacia, e não mais fica restrito a um único município. Sua definição fica mais abrangente também. Ela passa a ser entendida como unidade constituída por outros elementos, além dos naturais, como os componentes sociais, que estão fortemente inter-relacionados (SECTMA, 2007:19).

Bacia hidrográfica, portanto, não é apenas o rio e seus afluentes, mas também os componentes sociais que a integram. É necessário, então, a flexibilização da compreensão do conceito de bacia hidrográfica, mediantes a constituição de comitês em adequação aos distintos componentes sociais e sua atuação.

Apropriando-se de tal perspectiva, o COBH (Comitê da Bacia Hidrográfica) aprovou um plano diretor de recursos hídricos para aplicação de recursos financeiros com o propósito de conservar, proteger e recuperar a bacia do rio Ipojuca, além da promoção e divulgação de debates que incluiria a participação da população que circunda o rio e dele se utiliza. Os objetivos do Comitê, portanto, são:

Prioriza as ações referentes ao uso da água, definições da política em geral e das estratégias setoriais de interfaces com a gestão hídrica, para a melhoria da qualidade de vida, o fortalecimento da gestão hidro-ambiental, a melhoria do meioambiente natural e o controle do uso das águas na Bacia do rio Ipojuca (ALVES, 2007:88).

Entre as diversas competências dos comitês está a capacidade de aglutinar dados, apropriando-se de informações que poderão ser transformadas a favor dos interesses sociais e que auxilie e possibilite à sociedade a participação ativa na preservação dos rios e no monitoramente de políticas públicas. Esses comitês são reconhecidos e legitimados pelo próprio Estado e abarcam tanto as bacias hidrográficas sob o domínio de águas estaduais, nascente e foz do rio principal abrange um mesmo estado, como sob o controle de águas federais, ou seja, as áreas drenadas do rio principal são compartilhadas por mais de um estado. 
Outro projeto para preservação e revitalização do rio Ipojuca é Agenda 21. Esse documento é composto por recomendações e referências sobre como obter o "desenvolvimento sustentável", ou seja, como utilizar os recursos naturais sem esgotá-los, garantindo que as futuras gerações tenham acesso aos recursos e ao Ambiente "equilibrado".

A Agenda 21 começou a ser desenvolvida a partir de 1989, em uma reunião das Nações Unidas cujo propósito era pensar o Ambiente e o desenvolvimento. A Conferência das Nações Unidas para o Meio Ambiente e Desenvolvimento, conhecida como ECO-92 ou RIO-92 deu continuidade a esse projeto e destacou a importância de compreender as peculiaridades de cada região ao elaborar o estudo que visa à conservação dos ecossistemas locais e mundiais.

Os países que participaram da Conferência RIO-92 comprometeram-se em implementar ações de preservação ambiental nas seguintes dimensões: econômica e sociais, como 0 combate a miséria e a pobreza, aumentar o número de pessoas com acesso a água e sistema de esgoto, incentivar e efetivar a inclusão social e consciência ambiental e propor meios para a conservação dos recursos naturais e ecossistemas. Para o historiador norte-americano, Donald Worster, o grande dilema humano é "enfrentar o antigo problema da humanidade, que tem que se alimentar sem degradar a fonte básica da vida" (WORSTER, 2002, p. 39).

Em seu artigo Pensando como um rio (2008), Worster expôs a situação da agricultura no Oeste norte-americano e a má utilização dos rios naquela região gerando a salinização do solo e uma possível escassez de água em tempo próximo bem como sua contaminação. Ele também demonstrou que a maior parte dos aquíferos é empregada nos usos industriais e na agricultura.

Situação semelhante ocorre com a água da Bacia do rio Ipojuca onde 49,2\% são destinadas ao consumo animal, 20,8\% para a indústria, 18,1\% para a irrigação, 4,6\% para 0 consumo humano, 0,7\% para a geração de energia e 6,6\% para outras atividades (ALVES, 2007). O grande dispêndio de água relativo ao consumo animal deve-se ao fator da região Agreste ser uma área onde a pecuária leiteira, é intensa, inclusive dentro do território indígena.

A concretização da Agenda 21 para o Ipojuca, que resultaria em mais e maiores ações para a revitalização e conservação do rio, enfrenta obstáculos, tais como: falta de recursos financeiros e apoio de órgãos municipais, estaduais e federais; ausência de infra-estrutura física; e pouco comprometimento por parte dos vários membros participantes da Agenda (CARMO, 2002).

Outros órgãos e instâncias também são responsáveis pela preservação do Ambiente, em específico, dos recursos hídricos, em âmbito estadual ou nacional, são eles: Conselho Nacional de Recursos Hídricos (CNRH), colegiado que discorre sobre questão da utilização da água, seja no uso doméstico ou industrial, e que reúne entidades públicas, usuários e 
organizações civis; Secretaria de Recursos Hídricos (SRH) e Secretaria de Ciência, Tecnologia e Meio Ambiente (SECTMA), responsável por verificar a qualidade da água em rios, barragens, adutores e açudes; e a Agência Nacional de Águas (ANA), órgão que auxilia na elaboração e determina o cumprimento das diretrizes do PNRH (Programa Nacional Recursos Hídricos) que propõe medidas e destina recursos para o "bom uso" da água.

\section{Memórias sobre o Ipojuca e a Barragem Pão-de-Açúcar}

Desde a antiguidade que os estudiosos perceberam o valor da água e atribuíram a esse elemento a fonte da vida. Hipócrates, "médico" grego, que viveu por volta de 460-377 a.C. afirmou: "Ao chegar numa cidade desconhecida devesse observar o cuidado com a água usada pelos seus habitantes" (SILVA, 2007:05). A água é diretamente utilizada por todos os seres vivos. É também, elemento representativo dos valores sociais, culturais e ambientais, além de fator de produção de vários bens de consumo, intermediário e final, sendo, portanto, fundamental para o desenvolvimento de quase todas as atividades realizadas pelo homem (ZARPELON, 1996).

Os índios Xukuru estabelecem uma relação simbólica com a terra e seus recursos, por compreender a sua importância no sustento e na continuidade da afirmação étnica do grupo. Para evidenciar essa relação utilizaremos as memórias, pois, "A memória estar em cada passo que damos, idéias pensadas, ações realizadas. A memória estar presente em tudo e em todos" (SANTOS, 2009;25-26).

A memória também foi utilizada pelo pesquisador francês Michel Pollak como fonte de estudo. Ele analisou como a memória está associada ao processo de construção e (re)afirmação da identidade:

\footnotetext{
A memória é um elemento constituinte do sentimento de identidade, tanto individual como coletiva, na medida em que ela é também um fator extremamente importante do sentimento de continuidade e de coerência de uma pessoa ou de um grupo em sua reconstrução de si. A memória também sofre flutuações que são função do momento em que ela é articulada, em que ela está sendo expressa. As preocupações do momento constituem um elemento de estruturação da memória (POLLAK, 1992:4-5).
}

A memória é por isso essencial para a coesão de grupos e para sua permanência. 0 sociólogo francês, Maurice Halbwachs, não considerou a memória nem como um atributo da condição humana, nem a partir de seu vínculo com o passado, mas sim como resultado de representações coletivas construídas no presente, que tinham como função manter a sociedade coerente e unida (HALBWACHS, 1990). 
Como forma de afirmação da presença dos índios Xukuru na Serra de Ororubá e, portanto, o direito a obtenção do território, temos a utilização das memórias por aquele grupo indígena, como podemos perceber na fala do senhor Juvêncio Balbino da Silva, morador na aldeia Cana Brava; "Aqui não tinha branco não! Quer dizer, no tempo da minha avó. No tempo da minha avó, ela dizia que aqui, mode os brancos mesmos, porque os brancos foram entrando, foram entrando e aí tomou, foram tomando" (SILVA, 2008:109).

Outra vez a memória é acionada para confirmação da presença indígena no município anterior ao período colonial, pois o nome do município teria sido dado pelos Xukuru por se tratar de um local banhado pelos vales dos rios Ipojuca, Ipanema e Moxotó e ter uma produção de peixe bastante elevada, fato ratificado pelo geógrafo Hilton Sette em seu livro "Pesqueira: aspectos de sua geografia urbana e de suas inter-relações regionais" (SETTE, 1956), e repetido até hoje, como se pode ver no discurso do senhor "Vinvin", da Aldeia Passagem:

\begin{abstract}
Pesqueira, esse nome é por causa de um pesqueiro que os índios iam pescar lá, por conta desse pesqueiro a cidade passou a ser Pesqueira. Mas, na realidade mesmo era um poço que tinha que iam pescar lá, os nossos antepassados, no nosso território. Aí quando eles iam pescar eles diziam 'vamo pro pesqueiro'. Aí a cidade ficou como Pesqueira, mas era por causa do pesqueiro. ${ }^{3}$
\end{abstract}

A memória é base construtora de identidades, sendo elemento constitutivo de autoreconhecimento como pessoa ou membro de um grupo ou nação. Ela torna o tempo passado, vivo e repleto de significados, possibilitando que tradições, histórias e narrativas sejam repassadas aos mais jovens. Conforme a historiadora Lucília de Almeida Delgado "a História e a memória compete empreender a tarefa de busca evitar que o ser humano perca referências fundamentais à construção das identidades coletivas, que, mesmo sendo identidades sempre em curso, são esteios fundamentais do auto-reconhecimento do homem como sujeito de sua história" (DELGADO, 2006:36).

Na busca da afirmação de identidades, os sujeitos, de maneira individual e coletiva, mergulham em memórias não propriamente suas (memórias não vivenciadas), tecendo uma reconstrução espacial e temporal com o intuito de obter a consolidação da sua identidade étnica. Por meio da memória, as comunidades e os indivíduos podem, por exemplo, resgatar identidades ameaçadas e construir representações sobre sua inserção social e sobre sua cultura.

O sociólogo Paul Connerton também discorreu sobre a memória no livro "Como as sociedades recordam", e afirma que "as sociedades são comunidades que se auto-interpretam e 
que essas auto-interpretações são imagens que as sociedades criam e preservam de si próprias como sendo continuamente existentes" (1999:13). A memória é um suporte das identidades em suas dinâmicas e pluralidades, pois além de estabelecer diálogos com o passado permite a convicção de pertencimento a uma experiência ao mesmo tempo individual e compartilhada.

A identidade indígena foi negada pelo Estado e pela sociedade, como forma de omissão dos direitos ao território e as manifestações de suas expressões socioculturais. A população indígena presente em locais de antiga colonização, como o Nordeste, foram consideradas misturadas, sendo conhecidas como remanescentes de índios, pois havia perdido os sinais descritivos da "cultura original", o que o antropólogo, João Pacheco de Oliveira em seu artigo Uma etnologia dos "índios misturados"?, chamou de etnologias das perdas (OLIVEIRA, 2004), uma crítica aos estudos dos etnólogos que não compreendem as culturas, inclusive a indígena, como processos dinâmicos.

A nova historiografia indígena coloca o índio como sujeito da/na História e como participantes ativos na construção do Estado brasileiro e que hoje reivindicam o reconhecimento, garantia e respeito aos de seus direitos, aos seus territórios e a suas expressões socioculturais e diferenças étnicas. Entretanto, durante muito tempo a historiografia reservou ao indígena 0 passado e estabeleceu que sua cultura era imutável, estando os índios atualmente longe da "cultura original" e portanto assimilados e fadados ao total desaparecimento (ALMEIDA, 2010).

Para compreender as emergências étnicas ocorridas no século XX e XXI é necessário analisar a história e perceber como os povos indígenas foram capazes de reelaborar, em situações de contato, suas culturas, e fizeram o mesmo com suas identidades. 0 historiador John Manuel Monteiro no artigo 0 desafio da História indígena no Brasil discorre; "A extinção dos índios, tantas vezes prognosticada, é negada enfaticamente pela capacidade das sociedades nativas em sobreviver os mais hediondos atentados contra a sua existência" (1995:228).

Contrariando as perspectivas dos antigos pesquisadores, o número de indígenas no país vem aumentando de forma bastante significativa, principalmente em comparação ao restante da população, tendo o Brasil hoje 817 mil pessoas que se declaram índios. São cerca de 250 povos que falam 180 línguas. Os povos indígenas são diversos entre si e de nossa sociedade, revelando a riqueza de um Brasil pluriétnico.

O pesquisador Edson Silva, no artigo "Os povos indígenas e o Agreste: os Xukuru de Ororubá" discorre que "pelas memórias percebemos elos de uma história coletiva, de um pertencimento, em um conjunto de situações e experiências históricas sócioambientais que conferem uma identidade indígena Xukuru, baseada em um espaço ancestral comum, a Serra do 
Ororubá" (2008:125). Além do território, os recursos naturais disponíveis na região também são elementos importantes na coesão do grupo, que ao dispor deles podem permanecer na localidade evitando as constantes migrações que ocorreram entre a década de 50 á 90 do século XX. A utilização das águas da Barragem e consequentemente do rio Ipojuca estão inseridos nesses recursos.

O rio Ipojuca que cruza a região da Ribeira é lembrando nas memórias Xukuru como um rio irregular como podemos perceber na fala do senhor Amilton de Souza, morador da aldeia Passagem "Não tinha barragem não, antigamente era o rio. Aí era provisório, aquelas águas ali era poucos tempos. $E$ poucos tempos ficava poucos peixes, não era muito não. 0 rio era 0 Ipojuca, faz muito tempo, vinte anos atrás". 4

O já citado rio era utilizado principalmente para pesca e para o abastecimento dos domicílios. Era comum, também, o seu uso na agricultura doméstica. Por ser um rio intermitente naquela região, em determinados períodos do ano, como o verão, o rio secava, restando apenas poços naturais, cuja água ficava restrita, dificultando a pesca durante o estio, como podemos perceber na fala do senhor Edson Gomes de Souza, morador da Aldeia Pão-de-Açúcar:

Meus pais e avós não costumava pescar, eles vivia mais da caça e da agricultura, pescaria naquela época quase não tinha tão mais favorável. A Barragem onde mais tem possibilidade de pescaria, ela foi feita no tempo quando eu era menino, eu tinha dez anos. Quando a Barragem foi feita foi criada essa facilidade de trabalho através da pescaria. ${ }^{5}$

A quantidade de peixe, mesmo no período chuvoso, era pequena, dificultando a comercialização do produto, que geralmente era destinado apenas ao consumo residencial. A falta de materiais apropriados para a pesca, feita por anzol ou rede de arrasto, e a necessidade de auxilio dos amigos para a execução da tarefa, tornava ainda menor a oferta, pois o pouco obtido era dividido com todos os participantes, como relembra o senhor José Francisco de Oliveira, morador da aldeia Pão-de-Açúcar:

Meus avós, tios, eles pescava peixe pequeno, tilápia, traíra, são peixes que têm aqui no ambiente. Eles pescava no rio Ipojuca. Eles usava anzol e rede de arrasto, que é uma rede que pesca duas pessoa, aí sai arrastando, aí sai fora, quando sai fora tá o peixe. É rede pra lugar que não seja fundo. Antes não tinha essa Barragem, era o rio Ipojuca. Tinha ano que ele enchia e ano que era só o poço. Poço feito pela água. Eles pescava e conseguia só o normal pra viver, só pra consumir. ${ }^{6}$

\footnotetext{
${ }^{4}$ Amilton de Souza. Pesqueira, Área Indígena Xukuru, Aldeia Passagem. Entrevista realizada em 18/05/2010.

5 Edson Gomes de Souza. Pesqueira, Área Indígena Xukuru, Aldeia Pão-de-Açúcar. Entrevista realizada em $17 / 05 / 2010$.

6 José Francisco de Oliveira. Pesqueira, Área Indígena Xukuru, Aldeia Pão-de-Açúcar. Entrevista realizada em 19/07/2010.
} 
Entre os anos de 1987 e 1988 ocorreu à construção da Barragem Pão-de-Açúcar, e grande parte dela encontra-se dentro do território Xukuru. As águas do Ipojuca foram utilizadas para encher a Barragem que permanece conectada ao rio por meio de uma comporta. 0 processo de construção envolveu mão-de-obra indígena, como ainda lembrou o senhor José Francisco de Oliveira:

Trabalhei na construção da Barragem Pão-de-Açúcar como motorista. Carregava os materiais, botava os materiais para construir a barragem. Concreto, cimento, cal, tijolos, tijolos não, cimento, areia, muitas areias. Faz vinte e quatro anos.

Outro indígena, também morador na Aldeia Pão-de-Açúcar, o senhor José Edilson da Silva afirmou:

Eu trabalhei um ano como auxiliar de topografia. Eu trabalhava em uma firma que fazia a fiscalização. Eu colhia o material, a argila, que foi utilizada na Barragem. Se não prestasse, a gente jogava fora, se servisse iria pra Barragem. Muitas gentes da localidade trabalhou na Barragem, mas veio gente de todo o Brasil trabalhar. ${ }^{7}$

A água da Barragem é salobra, não sendo indicada para o consumo humano, principalmente devido a utilização de agrotóxico nas lavouras, algumas das quais cultivadas próximo ao reservatório, motivo inclusive que gera reclamações e discussões na comunidade. $A$ água, portanto, é reservada apenas para o consumo animal e utilidades domésticas, como, lavar pratos, roupas e higienização da casa e na agricultura.

No entanto, a principal utilidade da Barragem é para a pesca. Grande parte dos habitantes nas aldeias Pão-de-Açúcar e Passagem sobrevive desse trabalho, fato antes impossibilitado devido a irregularidade do rio como pode perceber no relato abaixo:

\begin{abstract}
Naquela época não existia essa Barragem, só existia o Ipojuca, essa Barragem tá com uns vinte e poucos anos de construção, por isso meus pais viviam da agricultura, na região da gente era quase só agricultura. Eles pescavam no rio pra cumer, no rio Ipojuca, perto da nascente do rio, pescavam pra cumer, e hoje aqui a pesca é pra vender, é pra sobrevivência da comunidade.
\end{abstract}

Com a Barragem a oferta de peixes aumentou, favorecendo que as horas destinadas à pesca diminuíssem, pois, se conseguia obter uma maior quantidade em menor tempo, possibilitando que outras atividades também recebessem atenção, como a criação de animais e a agricultura. A profundidade e extensão da Barragem, a inclusão de novos materiais para a pesca, como o barco, a tarrafa e as redes mais apropriadas, também permitiram um melhor retorno.

O senhor José Francisco de Oliveira também rememora o fato:

\footnotetext{
7 José Edilson da Silva, Aldeia Pão-de-Açúcar, Área Indígena Xukuru, Pesqueira-PE. Entrevista realizada em $30 / 05 / 2010$
} 
Eu pescava aqui mesmo, no rio Ipojuca, pegava a mesma coisa de peixe de hoje Naquele tempo eu passava o dia todinho pra pescar três quilos e agora dentro de três horas eu pego três quilos. Se eu passasse hoje o dia inteiro, eu pegava uns quinze quilos, mas não passo o dia inteiro porque não preciso, eu sou aposentado. $A$ Barragem melhorou cem porcento e o rio Ipojuca era mais longe, era mais longe.

De uma maneira quase unânime, a construção da Barragem é vista como algo positivo pelos indígenas da região atendida por ela. Quanto às reclamações, elas podem ser expostas em dois seguimentos: a inserção de peixes não típicos da área na Barragem - ação executada pelos "engenheiros de Recife"- pois esses animais se alimentam dos peixes nativos diminuindo sua produção e conseqüentemente a sua disponibilidade; e a falta de associações que ofereçam auxílio financeiro em determinados períodos - época de reprodução do animal -, onde é aconselhável interromper a pesca, para que o ecossistema não se desequilibre.

Após a retomada do território passaram a ser fontes de preocupação entre os Xukuru de Ororubá, a continuação do uso intensivo de "defensivos agrícolas". O prolongamento no uso desses agrotóxicos tem trazido consequências sérias para a saúde do agricultor, para o solo, as fontes de água, os animais e a vegetação que cerca toda a área plantada, conforme a narrativa do senhor José Elias Ferreira da Silva, morador da Aldeia Passagem "Dizem por aí que, o povo, que essas plantações na Barragem bota sujeita dentro da água. Essas plantações com veneno aí". 8

Apesar de afirmarem que a demarcação do território e a construção da Barragem trouxeram melhorias, garantindo maior quantidade de peixes, alguns indígenas reclamam de seus companheiros índios quanto ao tratamento com o rio e a Barragem. E asseguram que algumas condutas têm trazido prejuízos a todos os habitantes nas aldeias e vem requerendo um novo procedimento com o Ambiente.

\section{Considerações finais}

Esse texto faz parte de um estudo, ainda em estágio inicial, que pretende abranger outros aspectos tais como: o processo de construção da Barragem e seus impactos ambientais; memórias e mitos sobre o Ipojuca; a utilização da água para a agricultura e criação de animais; 0 "reflorestamento" e o aumento na disponibilidade da caça na área indígena após a demarcação do território; como os Xukuru percebem e veem o Ambiente e sua relação com o a identidade indígena.

\footnotetext{
8 José Elias Ferreira da Silva, Aldeia Passagem - Área Indígena Xukuru, Pesqueira-PE. Entrevista realizada em $30 / 05 / 2010$
} 


\section{Referências Bibliografias}

1. ALMEIDA, Maria Regina Celestino de. Os índios na História do Brasil. Rio de Janeiro: FGV, 2010.

2. ALVES, Manuel Augusto. Bacia do Rio Ipojuca: análise crítica para a construção de uma agenda 21. Recife: ITEP, 2007. (Dissertação Mestrado em Tecnologia Ambiental).

3. ANDRADE, M. C. de. A terra e o homem no Nordeste. $7^{\text {a }}$ ed. São Paulo: Cortez, 2005.

4. CARMO, Silvia Bacellar do. Agenda 21 Local do município de Santos: análise da elaboração e ações. São Carlos: UFSC, 2002. (Dissertação de Mestrado em Engenharia Urbana).

5. CAVALCANTI, Bartolomeu. No tacho, o ponto desandou: história de Pesqueira de 1930 a 1950. Recife: Baraúna, 2007.

6. CIRILO, José Almir. (Org.). 0 uso sustentável dos recursos hídricos em regiões semi-áridas. Recife: UFPE, 2007.

7. CONNERTON, Paul. Como as sociedades recordam. Oeiras: Celta, 1999.

8. CONSTITUIÇÃO DA REPÚBLICA FEDERATIVA DO BRASIL. Brasília: Centro Gráfico do Senado Federal, 1994.

9. $\mathrm{CPRH}$. Levantamento das fontes poluidoras na Bacia do rio Ipojuca. Recife: Ministério do Meio Ambiente, 2003.

10. CUNHA, Manuela C. da. (Org.). História dos índios no Brasil. São Paulo: Cia das Letras, 2008.

11. DELGADO, Lucilia de Almeida Neves. História Oral: memória, tempo e identidades. Belo Horizonte: Autêntica, 2006.

12. DRUMMOND, José Augusto. A História Ambiental: temas, fontes e linhas de pesquisas. In: Estudos Históricos. Rio de Janeiro, n. 8, p. 177-197. 1991.

13. FIALHO, Vânia. As fronteiras do ser Xukuru. Recife: Massangana, 1998.

14. FREYRE, Gilberto. Nordeste. $4^{\mathrm{a}}$ ed. Rio de Janeiro: Record, 1989.

15. GONÇALVES, Glaciene Mary da Silva. Agrotóxicos, saúde e ambiente na etnia Xukuru do Ororubá - PE. Recife: FIOCRUZ, 2008. (Dissertação Mestrado em Saúde Pública).

16. HALBWACHS, Maurice. A memória coletiva. São Paulo: Centauro, 2004.

17. LINS, Rachel Caldas. Áreas de exceção do Agreste de Pernambuco. Recife: SUDENE, 1989. 
18. MACIEL, José de Almeida. Pesqueira e o antigo Termo de Cimbres. Recife: Centro de Estudo de História Municipal, 1980.

19. MEIHY, José Carlos Sebe B.; HOLANDA, Fabíola. História Oral: como fazer, como pensar. São Paulo: Contexto, 2007.

20. MELO, Mário Lacerda de. Os agrestes: estudo dos espaços nordestinos do sistema gado-policultura de uso dos recursos. Recife: SUDENE, 1980.

21. MONTEIRO, John Manuel. (Org.). Confrontos de culturas: conquista, resistência, transformação. São Paulo: EDUSP, 1999.

22. MONTEIRO, John Manuel. O desafio da história indígena no Brasil. In: SILVA, Aracy Lopes da; GRUPIONI, Luis Donisete Benzi. A temática indígena na escola: novos subsídios para professores de $1^{\circ}$ e $2^{\circ}$ graus. Brasília: MEC/UNESCO, 1995.

23. OLIVEIRA, Kelly Emmanuelly de. Guerreiros de Ororubá. João Pessoa: UFPB, 2006. (Dissertação Mestrado em Sociologia).

24. OLIVEIRA, João Pacheco de (Org.). A viagem da volta: etnicidade, política e reelaboração cultural no Nordeste indígena. $2^{\mathrm{a}}$ ed. Rio de Janeiro, 2004.

25. PÁDUA, José Augusto. As bases teóricas da História Ambiental. In: Estudos Avançados. Rio de Janeiro, n. 24, p. 81-101, maio 2010.

26. PINHEIRO FILHO, João Domingos. Gestão Hídrica: participação e institucionalização no Comitê da Bacia hidrográfica do rio Ipojuca-PE. Recife: UFPE, 2005. (Dissertação de Mestrado em Gestão e Políticas Ambientais).

27. POLLAK, Michael. Memória e identidade social. In: Estudos Históricos. Rio de Janeiro, 1992 , n. 5 , p. 200-212.

28. REIS, José Carlos. As identidades do Brasil: de Varnhagen a FHC. Rio de Janeiro: FGV, 2000.

29. RIBEIRO, Darcy. Os índios e a civilização: a integração das populações indígenas no Brasil Moderno. $4^{\mathrm{a}}$ ed. Petrópolis: Vozes, 1982.

30. SANTOS, Hosana Celi de Oliveira e. Dinâmicas sociais e estratégias territoriais: a organização social Xukuru no processo de retomada. Recife: UFPE, 2009. (Dissertação Mestrado em Antropologia).

31. SANTOS, Myrian S. dos. Memória coletiva \& teoria social. São Paulo: Annablume, 2003.

32. SECTMA. Gestão integrada de resíduos sólidos na Bacia do rio Ipojuca. Recife: Ministério do Meio Ambiente, 2007. 
33. SETTE, HILTON. Pesqueira: aspectos de sua geografia urbana e de suas interrelações regionais. Recife: Colégio Estadual de Pernambuco, 1956.

34. SILVA, Edson H. Xukuru: memórias e histórias dos índios da Serra do Ororubá (Pesqueira/PE), 1950-1988. Campinas: UNICAMP, 2008. (Tese Doutorado em História Social).

35. SILVA, Sivaldo Souza. Diagnóstico do sistema de gerenciamento dos recursos hídricos no município de Pesqueira. Recife: ITEP, 2007. (Dissertação Mestrado em Tecnologia Ambiental).

36. SCHOTT, Dieter. Urban environmental history: what lessons are there to be learnt?. Helsinki: Boreal Environment Research, 2004. p. 519-528.

37. TUCCI, Carlos E. M., BRAGA, Benedito. (Orgs.). Clima e recursos hídricos no Brasil. Porto Alegre: ABRH, 2003.

38. WORSTER, Donald. Doing environmental history. In: WORSTER, Donald. The ends of the Earth. Cambridge, Cambridge University Press, 1988, p. 289-307.

39. Pensando como um rio. In: ARRUDA, Gilmar (Org.). A natureza dos rios: história, memória e territórios. Paraná: UFPR, 2008, p. 27-46.

40. Transformações da terra: para uma perspectiva agroecológica na história. São Paulo: Clacso, 2003.

41. ZARPELON, A. Água: preservar é preciso. Curitiba: Sanare, v. 5 n.5, jan-jun, 1996.

Artigo recebido em: 01/10/2011

Aprovado em: 27/11/2011 